http://jmscr.igmpublication.org/home/ ISSN (e)-2347-176x ISSN (p) 2455-0450

crossref DOI: https://dx.doi.org/10.18535/jmscr/v9i5.21

\title{
Role of methylprednisolone versus Dexamethasone in COVID-19 Pneumonia: A comparative study
}

\author{
Authors \\ Kouser Benazir ${ }^{1}$, Nayla Farooq ${ }^{2}$, Shazia Ashraf ${ }^{3 *}$ \\ ${ }^{1}$ Lecturer, Department of Anesthesiology \& Critical Care, Govt. Medical College, Srinagar, India \\ ${ }^{2,3}$ Senior Resident, Department of Anesthesiology \& Critical Care, Govt. Medical College, Srinagar, India \\ *Corresponding Author \\ Dr Shazia Ashraf \\ Senior Resident, Department of Anesthesiology \& Critical Care, Govt. Medical College, Srinagar, India
}

\begin{abstract}
Background: In the first half of 2020 COVID-19 disease has already converted into a global pandemic. Various treatment options were being tried all over the globe. Corticosteroids have been considered in medication since long times and they are extensively endorsed.

Objective: Various treatment therapies were being tried all over the globe to curb the COVID-19 disease. As studies showed encouraged effects of corticosteroids in COVID-19 pandemic, hence we conducted this study to compare the efficacy and safety of low doses of methylprednisolone and dexamethasone in moderate to severe COVID-19 symptoms.

Methods: A study on 300 patients, 150 patients in group A who received dexamethasone and 150 patients in group $B$ who received methylprednisolone was conducted in the department of Aneasthesiology and critical care pain management in Govt; Medical collage Srinagar (J\&K) over the period of six months. Group A received $8 m \mathrm{mg}$ BD dexamethasone and group B received methylprednisolone $1 \mathrm{mg} / \mathrm{kg} /$ day in 2 divided doses for 8 days during their stay in our ICU. The remaining treatment was the same in both the groups including anticoagulants and antibiotics. We revived the following parameters after 8 days, serum ferritin levels and CRP levels among the study population.

Results: The initial mean serum ferritin levels of group A decreases after administration of dexamethasone. Similarly the initial ferritin levels of group B also decreased after administration of methylprednisolone. Same results were obtained for CRP levels in both the groups. However, dexamethasone was significantly more effective than methylprednisolone ( $p<0.05)$.

Conclusion: steroids are an effective tool in the treatment of COVID-19 due to their ability to suppress the immune response along with their anti-inflammatory properties. In the treatment of COVID-19 patients, use of dexamethasone can lead to a further decrease in mortality as compared to methylprednisolone.

Keywords: Methylprednisolone, Dexamethasone, COVID-19, pneumonia.
\end{abstract}

\section{Introduction}

The novel corona virus (CoV)-2019 pandemic has turned out to be a huge public health concern. The virus is diagnosed as SARS CoV-2, and the ailment due to this virus is known as $\mathrm{CoV}$ ailment-2019 (COVID-19). Even though maximum sufferers are asymptomatic, in lots of sufferers, COVID-19 manifests as pneumonia, 
acute respiratory distress syndrome (ARDS), septic shock and death ${ }^{[1,2]}$. Some of the antiviral medicinal drugs have already been accepted in different countries. But, there's no drug to be had to deal with the excessive manifestation of ARDS in COVID-19 cases. The hazards of severity and mortality of COVID-19 ranged from 12.6-23.5\% and $2-4.4 \%$, respectively. ARDS has been the most common complication of severe COVID-19 cases, with occurrence ranging from 15.6 to $31 \%$ [3].

Steroids are used to deal with numerous lung infections. Animal research implies that using corticosteroids improved the effects in viral infections ${ }^{[4,5]}$. Consequently, corticosteroids have been used to manipulate lung infections throughout the outbreaks of the SARS and the Middle East respiration syndrome (MERS) ${ }^{[6,7]}$.

Steroids were used formerly in respiration ailments like asthma, COPD, excessive bacterial pneumonia and acute respiratory syndrome. The use of steroids in COVID-19 ailment remains controversial ${ }^{[8]}$. Research has suggested steroids to lessen infections ${ }^{[9,10]}$. However steroids suppress the patient's immunity making him vulnerable to superadded infections ${ }^{[11]}$. Reports in Michigan reviews right effects of early remedy with short route of steroids ${ }^{[12]}$. In Michigan reports also used methylprednisolone for treatment of COVID pneumonia. Studies in china have additionally suggested using corticosteroids in COVID pneumonia ${ }^{[13]}$. Recently the recuperation trial in UK confirmed dexamethasone (a corticosteroid), to be the handiest drug capable of lessening mortality in excessive COVID ailment ${ }^{[14]}$.

Recently, dexamethasone, a synthetic corticosteroid, has proven to lower the mortality in COVID-19 sufferers who have been on ventilators or oxygen therapy. It is the handiest remedy to lessen the mortality in COVID-19 brought about ARDS so far. Subsequently, many nations have adopted dexamethasone in seriously sick patients.
The current study was directed on 300 Corona virus patients with moderate to serious Coronavirus sickness in the department of Aneasthesiology in Govt; Medical collage Srinagar (J\&K) over a time of a half year.

\section{Methods}

300 Patients chose for study were conceded in Coronavirus unit who satisfied the incorporation standards and marked educated assent. Standard oxygen saturation and clinical discoveries were noted. Chest x-beam was done on confirmation. Base line examinations were sent, starting degrees of CRP (C-receptive protein) and serum ferritin levels were noted down.

\section{Study Population}

Patients were similarly partitioned in to two groups Group A $(n=150)$ and Group B $(n=150)$. All patients in each group got (Group A got 8mg BD dexamethasone and group B got methylprednisolone $1 \mathrm{mg} / \mathrm{kg} / \mathrm{day}$ in 2 separated dosages for 8 days during their stay in our ICU). The leftover treatment was something very similar in both the groups including anticoagulants and anti-microbials.

Patients with oxygen dip $<93 \%$ on room air with ordinary chest x-ray, CRP between 28 to 40 and serum ferritin 10 to 150 , were named as having moderate Coronavirus infection. Patients with CRP $>50$, serum ferritin $<10$ and having penetrates on chest $\mathrm{x}$-ray at the hour of affirmation were considered having extreme Coronavirus sickness. Intravenous methylprednisolone in a portion of $1 \mathrm{mg} / \mathrm{kg} /$ day in 2 isolated dosages or dexamethasone $8 \mathrm{mg}$ twice in a day IV were given to substitute patients for 8 days. Following 8 days, we again recorded the oxygen saturation, CRP level, serum ferritin levels and rehash chest x-ray discoveries. Oxygen was given by high stream nasal cannula and poly mask. Patients were intubated in ICU if clinical condition decayed as well as mechanical ventilation was required. We noticed the improvement in clinical, radiological and biochemical boundaries of the patient on day 0 
that is confirmation day and later on day 8 subsequent to giving steroids (methylprednisolone or dexamethasone) for 8 days. We likewise associated the impact of steroids with level of CRP and serum ferritin levels at season of affirmation and presence of penetrates on beginning chest $\mathrm{X}$-ray in our patients and noticed the improvement in CRP, serum ferritin levels and $\mathrm{X}$-ray subsequent to giving corticosteroids. In this manner we thought about the distinction in result in patients getting methylprednisolone or dexamethasone.

Information was dissected utilizing SPSS adaptation 25.0. Mean and standard deviation was figured for quantitative factors while recurrence and rate were determined for downright factors. Combined example t-test was applied for correlation of the two groups.

\section{Results}

A profile of 300 patients was taken in this comparative study conducted at Govt; Medical collage Srinagar (J\&K). All the study population in the both the groups were comparable regarding their demographic profile (Table 1). 150 patients received dexamethasone and 150 received methylprednisolone.

Table 1: Demographic profile of the study population

\begin{tabular}{|l|c|c|c|}
\hline Variables & $\begin{array}{c}\text { Group A } \\
\mathrm{N}=150\end{array}$ & $\begin{array}{c}\text { Group B } \\
\mathrm{N}=150\end{array}$ & P value \\
\hline Age & $56.75 \pm 9.11$ & $58.67 \pm 10.55$ & 0.785 \\
\hline Sex M/F & $92 / 58$ & $88 / 62$ & 0.821 \\
\hline Smokers/ Non smokers & $85 / 65$ & $90 / 60$ & 0.431 \\
\hline
\end{tabular}

In both groups, the baseline values of CRP, serum ferritin levels, chest $\mathrm{X}$ ray and oxygen saturation at the time of admission in our ICU (Table2).

Table 2: Base line values of study population

\begin{tabular}{|l|c|c|c|}
\hline Variables & Group A & Group B & P value \\
\hline $\mathrm{SPO}_{2}$ & $92.5 \pm 2.5$ & $91.9 \pm 3.2$ & 0.561 \\
\hline CRP & $128.5 \pm 14.8$ & $125.8 \pm 15.9$ & 0.632 \\
\hline Serum Ferritin & $69.7 \pm 18.5$ & $73.5 \pm 21.4$ & 0.731 \\
\hline
\end{tabular}

Serum Ferritin as well as CRP Levels decreased after the administration of Dexamethasone and methylprednisolone in both groups (fig 1,2)

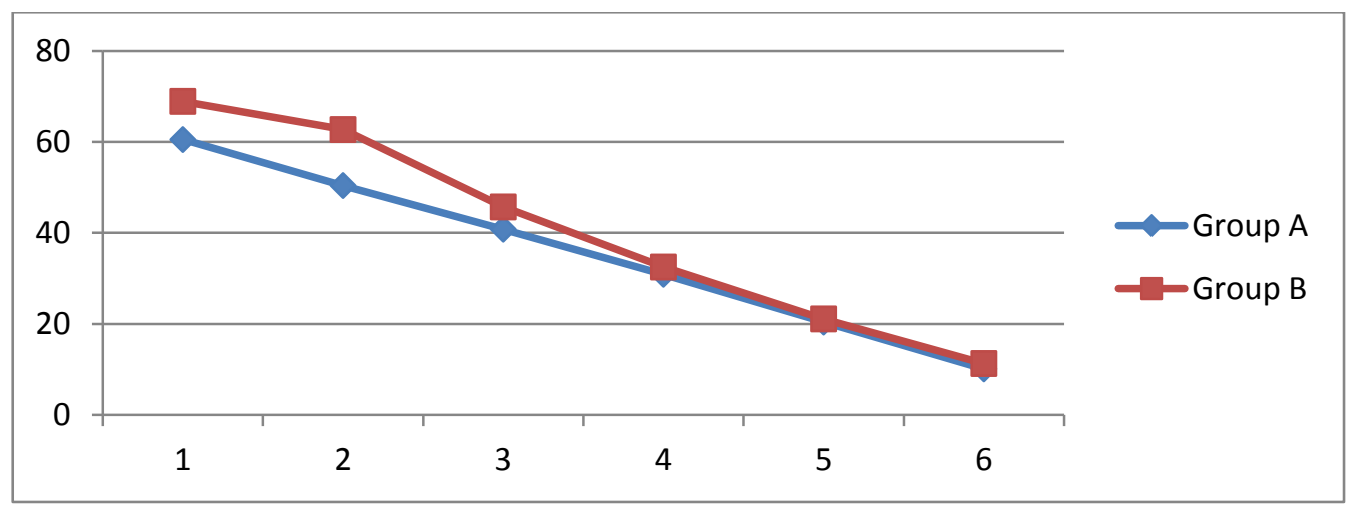

Fig 1: Serum Ferritin levels 


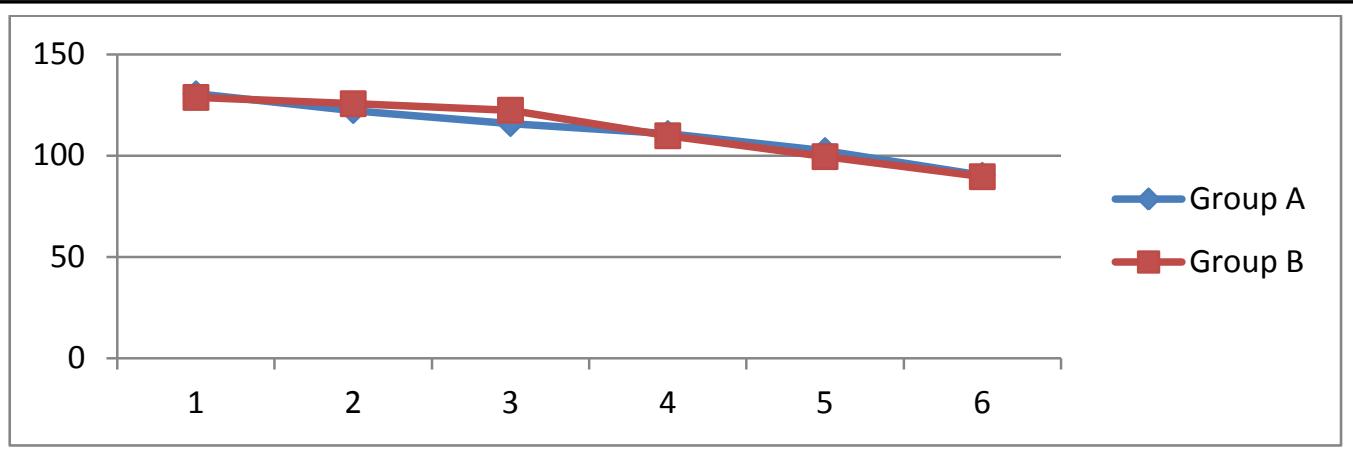

Fig 2: CRP Levels

Mean oxygen requirement was reduced from 13.5 L on day 0-9.5 litres on day 8. There was significant reduction in CRP from 136.5 to 74.8 (p $=0.0001)$. In methylprednisolone group, Mean oxygen requirement reduced from $13.8 \mathrm{~L}$ to $8.8 \mathrm{~L}$ on day 8. Mean CRP reduced from 125.5 to 55.07 in 8 days which is a quite significant improvement ( $\mathrm{p}<0.0001)$. Only 17 (11.33\%) patient died among those who received dexamethasone while $24(16 \%)$ patients died among those receiving methylprednisolone. There was also improvement in serum ferritin levels significantly in group A as compared to group B.

Dexamethasone group showed greater improvement as compared to methylprednisolone group and fast recovery rate as well as less mortality rates was seen in group A as compared to group B with statistically significant values (Table 3).

\section{Table 3}

\begin{tabular}{|l|c|c|c|}
\hline Variables & $\begin{array}{c}\text { Group A } \\
\mathrm{n}=150\end{array}$ & $\begin{array}{c}\text { Group B } \\
\mathrm{N}=150\end{array}$ & P value \\
\hline Recovery rate & $97 \%$ & $82 \%$ & 0.001 \\
\hline Mortality & $11.33 \%$ & $16 \%$ & 0.004 \\
\hline Improvement in chest X ray & $95 \%$ & $75 \%$ & 0.002 \\
\hline
\end{tabular}

\section{Discussion}

Reasonable utilization of corticosteroids has been accounted for in patients with COVID-19 ${ }^{[2]}$. A few examinations have revealed the impact of corticosteroids in COVID-19. An efficient audit and meta-investigation assessed clinical highlights and treatment results of COVID-19 from all distributed examinations up to 15March 2020. Pooled information from 16 examinations with 2407 patients announced the utilization of corticosteroids. The pace of mortality and ARDS were $7.2 \%$ (95\% CI: $1.7-15.4)$ and $22.7 \%$ (95\% CI: 9.9-38.6), while the general paces of mortality and ARDS were 4.3 and $18.4 \%$, separately. Metarelapse investigation of the information uncovered a relationship between corticosteroid use and $\mathrm{ARDS}^{[15]}$. Another efficient survey that gathered distributions until 15 March 2020 assessed the utilization of corticosteroids in COVID-19. The audit doesn't completely uphold the standard utilization of corticosteroids in COVID-19. Out of the four investigations remembered for the examination, two announced conceivable damage by the utilization of corticosteroids (expanded danger of ICU confirmations [72.2 versus 35.3\%] and postponed viral freedom [15 versus 8 days]). Then, in another investigation, methylprednisolone fundamentally diminished the danger of mortality by $62 \%$ in patients with serious pneumonia (risk proportion: $0.38 ; 95 \% \mathrm{CI}$ : $0.20-0.72)^{[16]}$.

There have been number of studies on dexamethasone and methylprednisolone alone in treatment of Coronavirus however in this investigation we did the correlation somewhere in the range of dexamethasone and methylprednisolone. In our examination we chose 300 patients with moderate to serious Coronavirus 
sickness, they were appointed to two gatherings by accommodation testing procedure. The gatherings were equivalent according to as age and sex is concerned. Comparable norm of care was given to the two gatherings including the utilization of anti-toxins and anticoagulants. We noticed that dexamethasone bunch shows stamped improvement when contrasted with methylprednisolone bunch.

In a review observational investigation of COVID-19 patients under 50 years old, corticosteroid treatment improved the manifestations. By and by, it deferred viral freedom in patients ${ }^{[17]}$. In another review examination, patients were isolated into extreme and non-serious gatherings to adapt to benchmark information irregularity. Patients were on lowportion methylprednisolone. Viral freedom was not postponed in patients who were on corticosteroids when contrasted and the controls. It was noticed both in serious and non-extreme gatherings $^{[18]}$. For a situation arrangement of 21 COVID-19 patients, who were given a short course of dexamethasone, CRP levels diminished essentially at the hour of release. None of the patients had a heightening to mechanical ventilation. The mean length of emergency clinic stay was discovered to be 7.8 days $^{[19]}$. Li et al., 2020 tracked down that lone high-portion corticosteroid (80 mg/day methylprednisolone) deferred the viral leeway in COIVD-19 patients while the low portion didn't ${ }^{[20]}$. A review studybased inclination score-coordinated with companion tracked down that more patients in the corticosteroid bunch advanced to extreme COVID19 (11.4 versus 2.9\%; $\mathrm{p}=0.353$ ). Other boundaries, for example, emergency clinic stay and term of viral shedding were drawn out, while fever time abbreviated, however, these progressions were not measurably huge ${ }^{[21]}$.

Up until this point, the biggest preliminary on different treatment modalities of Coronavirus is the Recovery preliminary led in UK which demonstrates viability of dexamethasone. It shows essentially less mortality in dexamethasone bunch when contrasted with standard consideration bunch anyway this distinction was more critical in patients requiring oxygen as well as ventilatory help. By and large, 482 (22.9\%) patients in dexamethasone bunch while 1110 (25.7\%) in standard consideration bunch lapsed inside 28 days of the mediation ${ }^{[8]}$. Recuperation preliminary had a huge data set of in excess of 4000 patients though our investigation had just 300 patients. Both methylprednisolone and dexamethasone have a part in administration of extreme respiratory sickness and our examination shows huge distinction in result in dexamethasone bunch. Dexamethasone is the solitary medication demonstrated to diminish the death rate in COVID-19 patients. Be that as it may, it is valuable just in serious instances of COVID-19. In patients who don't need oxygen or mechanical ventilation, dexamethasone somewhat expanded mortality ${ }^{[22]}$. Then again, the vast majority of the other accessible proof propose corticosteroid treatment in COVID-19 has either no advantages or hurtful. It prompted extreme sickness, expanded mortality also, postponed viral freedom. Be that as it may, these information come from review and observational investigations, consequently making it hard to finish up. As more broken down individuals are bound to have gotten corticosteroids, higher mortality can't be credited to the corticosteroid treatment alone. Another worry with corticosteroid treatment is deferred viral freedom. The immunosuppressant impact of corticosteroids is perhaps disabling the viral freedom by have insusceptibility. In bacterial pneumonia, suitable anti-toxin treatment is compelling in clearing the microorganisms. It isn't the situation with the viral disease. With the not so viable antiviral treatments, immunosuppressant corticosteroids could deteriorate the viral freedom. A few confirmations recommend that low-portion corticosteroids didn't deteriorate the viral leeway in COVID-19. Early, short course of corticosteroid utilize diminished the mortality and length of emergency clinic stay in other $\mathrm{CoV}$ contaminations. Then again, results from the 
RECOVERY preliminary unmistakably show that just extreme COVID-19 patients profited by dexamethasone treatment. While low-portion corticosteroid gives off an impression of being powerful yet an early application isn't. Hyperglycemia is another notable unfriendly impact of corticosteroid treatment. It expects importance here on the grounds that diabetes is one of the danger factors for serious inconveniences of COVID-19 and its mortality. Shockingly, the RECOVERY preliminary outcomes didn't give information on diabetes patients who were on dexamethasone. In this manner, without any immediate proof, it is prudent to follow the set up conventions in utilizing corticosteroids for treating the COVID19 patients with diabetes.

\section{Limitation}

The major limitation of our study was that we did not have a control group and the patient number in both groups was not enough. We did not check viral load of the patients of COVID-19. Our patients were not followed up after discharge from hospital.

\section{Conclusion}

Steroids are an effective tool in the treatment of COVID-19 due to their ability to suppress the immune response along with their antiinflammatory properties. In the treatment of COVID-19 patients, use of dexamethasone can lead to a further decrease in mortality as compared to methylprednisolone and effective in management of moderate to severe COVID-19 disease.

\section{Conflict of Interest: Nil \\ Funding: Nil}

\section{References}

1. Guo Y-R, CaoQ-D,Hong Z-S et al. The origin, transmission and clinical therapies on coronavirus disease 2019 (COVID-19) outbreak: an update on the status. Mil. Med. Res. 7(1), 1-10 (2020).

2. Guan $\mathrm{W}, \mathrm{Ni} \mathrm{Z}, \mathrm{Hu} \mathrm{Y}$ et al. Clinical characteristics of coronavirus disease 2019 in China. N. Engl. J. Med. 382(18), 17081720 (2020).

3. Li X, Ma X. Acute respiratory failure in COVID-19: is it "typical" ARDS? Crit. Care 24(1), 198 (2020).

4. DeDiego ML, Nieto-Torres JL, ReglaNava JA et al. Inhibition of NF- $\mathrm{B}-$ mediated inflammation in severe acute respiratory syndrome coronavirus-infected mice increases survival. J. Virol. 88(2), 913-924 (2014).

5. Chan JF-W, Yao Y, Yeung M-L et al. Treatment with lopinavir/ritonavir or interferon- $\beta 1 \mathrm{~b}$ improves outcome of MERS-CoV infection in a nonhuman primate model of common marmoset. $J$. Infect. Dis. 212(12), 1904-1913 (2015).

6. Arabi YM, Mandourah Y, Al-Hameed F et al. Corticosteroid therapy for critically ill patients with Middle East respiratory syndrome. Am. J. Respir. Crit. Care Med. 197(6), 757-767 (2018). 7. Stockman LJ, Bellamy R, Garner P. SARS: systematic review of treatment effects. PLoS Med. 3(9), e343 (2006).

7. M. Cascella, M. Rajnik, A. Cuomo, S.C. Dulebohn, R. Di Napoli, Features, evaluation, and treatment of coronavirus (COVID-19), in: StatPearls. Treasure Island (FL), StatPearls Publishing, 2020. August 10.

8. Y. Wang, W. Jiang, Q. He, et al., A retrospective cohort study of methylprednisolone therapy in severe patients with COVID-19 pneumonia, Sig Transduct Target Ther 5 (2020) 57, https://doi.org/10.1038/s41392-020-01582.

9. Z. Ye, Y. Wang, L.E. Colunga-Lozano, et al., Efficacy and safety of corticosteroids in COVID-19 based on evidence for 
COVID-19, other coronavirus infections, influenza, community-acquired pneumonia and acute respiratory distress syndrome: a systematic review and meta-analysis, CMAJ (Can. Med. Assoc. J.) 192 (27) (2020).

10. W. Zhang, Y. Zhao, F. Zhang, et al., The use of anti-inflammatory drugs in the treatment of people with severe coronavirus disease 2019 (COVID-19): the Perspectives of clinical immunologists from China, Clin. Immunol. 214 (2020) 108393, https://doi.org/10.1016/j.clim.2020.108393

11. R. Fadel, A. Morrison, A. Vahia, Z. Smith, Z. Chaudhry, P. Bhargava, et al., Early Short-Course Corticosteroids in Hospitalized Patients with COVID-19, Clinical Infectious Diseases, 2020.

12. Coronavirus Disease 2019 (COVID-19), Centers for Disease Control and Prevention, 2020 [cited 29 August 2020].

13. G. Wang, C. Wu, Q. Zhang, et al., Creactive protein level may predict the risk of COVID-19 aggravation, Open Forum Infect Dis 7 (5) (2020), https://doi.org/ 10.1093/ofid/ofaa153 ofaa153. Published 2020 Apr 29.

14. E. Wilkinson, RECOVERY trial: the UK COVID-19 study resetting expectations for clinical trials, BMJ (2020) m1626.

15. Zhang JJY, Lee KS, Ang LW, Leo YS, Young BE. Risk factors of severe disease and efficacy of treatment in patients infected with COVID-19: a systematic review, meta-analysis and meta-regression analysis. Clin. Infect. Dis. doi: 10.1093/cid/ciaa576 (2020).

16. Veronese N, Demurtas J, Yang L et al. Use of corticosteroids in coronavirus disease 2019 pneumonia: a systematic review of the literature. Front. Med. 7(April), 1-6 (2020).
17. Gong Y, Guan L, Jin Z, Chen S, Xiang G, Gao B. Effects of methylprednisolone use on viral genomic nucleic acid negative conversion and CT imaging lesion absorption in COVID-19 patients under 50 years old. J. Med. Virol. doi: 10.1002/jmv.26052 (2020).

18. Fang X, Mei Q, Yang T et al. Low-dose corticosteroid therapy does not delay viral clearance in patients with COVID-19. J. Infect. 81(1), 147-178 (2020).

19. Selvaraj V, Dapaah-Afriyie K, Finn A, Flanigan TP. Short-term dexamethasone in Sars-CoV-2 patients. R. I. Med. J. (2013) 103(6), 39-43 (2020).

20. Li S, Hu Z, Song X. High-dose but not low-dose corticosteroids potentially delay viral shedding of patients with COVID-19. Clin. Infect. Dis. doi: 10.1093/cid/ciaa829 (2020) (Epub ahead of print).

21. Yuan M, Xu X, Xia D et al. Effects of corticosteroid treatment for non-severe COVID-19 pneumonia: a propensity score-based analysis. Shock doi:10.1097/ SHK.0000000000001574 (2020).

22. The RECOVERY Collaborative Group. Dexamethasone in hospitalized patients with COVID-19: preliminary report. $N$. Engl. J. Med. doi:10.1056/NEJMoa2021436 (2020). 